\title{
SOBRE DEMOCRACIA, METODOLOGÍA Y DINERO. COMENTARIO A LA SENTENCIA DEL TRIBUNAL CONSTITUCIONAL FEDERAL ALEMÁN, DE 5 DE MAYO DE 2020, SOBRE EL PSPP
}

On democracy, methodology and money. Commentary on the PSPP Judgment of the German Federal Constitutional Court, of 5 May 2020

\author{
JOSÉ MARÍA RODRÍGUEZ DE SANTIAGO \\ Universidad Autónoma de Madrid \\ josemaria.rodriguez@uam.es
}

Cómo citar/Citation

Rodríguez de Santiago, J. M.a (2021)

Sobre democracia, metodología y dinero. Comentario a la Sentencia del Tribunal

Constitucional Federal Alemán, de 5 de mayo de 2020, sobre el PSPP.

Revista Española de Derecho Constitucional, 122, 295-331.

doi: https://doi.org/10.18042/cepc/redc.122.09

\section{Resumen}

Por primera vez en su historia, el Tribunal Constitucional Federal Alemán ha declarado ultra vires una sentencia del Tribunal de Justicia de la Unión Europea (y previas decisiones del Banco Central Europeo) y la considera sin efectos ni carácter vinculante en Alemania. Desde el punto de vista sustantivo, lo más relevante de la sentencia se refiere a la singular construcción alemana del principio democrático y a los reparos frente a la sustitución en la Unión Europea de la política democrática por el activismo de sus órganos independientes. Desde una perspectiva metodológica, el principio de proporcionalidad se utiliza como instrumento determinante para llevar a cabo el control del ultra vires. 


\title{
Palabras clave
}

Principio democrático; derecho fundamental a la autodeterminación democrática; principio de proporcionalidad; control del ultra vires; primacía del derecho de la Unión Europea; Public Sector Purchase Programme (PSPP).

\begin{abstract}
For the first time in its history, the German Federal Constitutional Court has declared a judgment of the Court of Justice of the European Union (and previous decisions of the European Central Bank) to be ultra vires, and considers it without effects or binding character in Germany. From the substantive point of view, the most relevant part of the decision refers to the unique German construction of the democratic principle and the objections to the replacement in the European Union of democratic politics by the activism of its independent bodies. From a methodological perspective, the principle of proportionality is used as a determining instrument to carry out the ultra vires control.
\end{abstract}

\section{Keywords}

Democratic principle; fundamental right to democratic self-determination; principle of proportionality; ultra vires control; supremacy of EU law; Public Sector Purchase Programme (PSPP). 


\section{SUMARIO}

I. PRESENTACIÓN: 1. Un primer vistazo a las cuestiones planteadas: democracia, metodología y dinero. 2. El proceso y las declaraciones de la sentencia. 3. Las reacciones inmediatas. II. TRES PRESUPUESTOS DE DERECHO CONSTITUCIONAL Y PROCESAL: 1. Teoría del Estado y reservas alemanas a la primacía del derecho de la Unión Europea. 2. El derecho fundamental a la autodeterminación democrática. 3. El recurso de amparo para la defensa del derecho fundamental a la democracia en cuestiones relativas a la integración europea. III. DEMOCRACIA: 1. El ultra vires europeo como «recorte» de la democracia alemana. 2. El reproche de la sustitución de la política democrática en la Unión Europea por la actuación de instituciones independientes. IV. METODOLOGÍA: 1. El principio de proporcionalidad y la distribución de competencias entre la Unión Europea y los Estados miembros. 2. ¿Ultra vires o simple ilegalidad? 3. La cuestión de la densidad del control judicial sobre el respeto por el BCE de los límites de sus competencias. V. DINERO: 1. La prohibición de las ayudas financieras a los Estados miembros (art. 123 TFUE). 2. La eventual distribución de pérdidas. VI. CONCLUSIÓN. Y AHORA, ¿QUUÉ? LA RESPUESTA EUROPEA FRENTE A LA CRISIS DEL CORONAVIRUS. BIBLIOGRAFIA.

\section{PRESENTACIÓN}

\section{UN PRIMER VISTAZO A LAS CUESTIONES PLANTEADAS: DEMOCRACIA, METODOLOGÍA Y DINERO}

Dos de los programas de compra de valores públicos aprobados por el Banco Central Europeo (en adelante, BCE) desde el comienzo de la crisis de la deuda soberana han dado lugar a dos conocidos conflictos sobre los que se han pronunciado en paralelo el Tribunal de Justicia de la Unión Europea (en adelante, TJ) y el Tribunal Constitucional Federal Alemán (en adelante, conforme a su denominación en ese idioma, BVerfG) ${ }^{1}$.

\footnotetext{
Agradezco a Luis Arroyo Jiménez que leyera e hiciera observaciones sobre una de las últimas versiones de este trabajo. También agradezco sus comentarios a los dos autores de los informes de evaluación. Este trabajo se concluyó y se envió a la Revista el 19 de octubre de 2020 . No se ha tenido en cuenta material publicado posteriormente.
} 
En el primer caso, planteado ante el BVerfG contra el programa denominado Outright Monetary Transactions (en adelante, OMT), aquel formuló la cuestión prejudicial ante el TJ que terminó con la STJ (Gran Sala) de 16 de junio de 2015 (Gauweiler, asunto C-62/14), para dictar después la Sentencia del BVerfG (Segundo Senado) de 21 de junio de 2016 (caso OMT), que contenía, en lo que ahora interesa, otro aviso más sobre el ejercicio por el tribunal alemán del control del ultra vires en actos de órganos de la Unión Europea. Este control ha sido delimitado progresivamente en sus contornos por la jurisprudencia del $\mathrm{BVerfG}^{2}$ desde sus sentencias de 8 de abril de 1987 (caso Kloppenburg) y de 12 de octubre de 1993 (caso Maastricht) ${ }^{4}$.

Es conocido que fue precisamente el asunto $O M T$ el primer caso en el que el BVerfG se decidió a plantear una cuestión prejudicial ante el TJ, conforme a la doctrina que el mismo Alto Tribunal alemán había establecido en su sentencia Honeywell: con carácter general, antes de ejercer el control del ultra vires en un acto de un órgano de la Unión Europea, el BVerfG debería promover la cuestión prejudicial (art. 267 TFUE), para dar al TJ oportunidad de pronunciarse sobre la interpretación de los tratados y la validez y la interpretación del acto cuestionado5. El OMT nunca llegó a ejecutarse, porque solo su presentación ya tranquilizó a los mercados financieros y determinó una subida de las bolsas y el mantenimiento de tipos de interés bajos en la eurozona ${ }^{6}$.

En 2015 el BCE aprueba otro programa de compra masiva de valores públicos en el mercado secundario, conocido como Public Sector Purchase Programme (PSPP), que, de nuevo, es objeto de un proceso constitucional ante del BVerfG, que vuelve a plantear la cuestión prejudicial. El TJ la resuelve con la STJ (Gran Sala) de 11 de diciembre de 2018 (Weiss, asunto C-493/17). $\mathrm{Y}$ es la resolución de aquel proceso constitucional a través de la Sentencia del BVerfG (Segundo Senado) de 5 de mayo de 2020 (caso PSPP) la que desencadena una tormenta sin precedentes en el ámbito de la política europea y entre los académicos del derecho público. Por primera vez en su historia, el BVerfG declara (parcialmente) ultra vires una sentencia del TJ (y las previas

\footnotetext{
Un repaso sintético de los casos más relevantes, por ejemplo, en Sauer (2020: 4-5).

3 Sentencia del BVerfG (Segundo Senado) de 8 de abril de 1987 (caso Kloppenburg), apdo. 54 y ss.

4 Sentencia del BVerfG (Segundo Senado) de 12 de octubre de 1993 (caso Maastricht), apdo. 106.

5 Sentencia del BVerfG (Segundo Senado) de 6 de julio de 2010 (caso Honeywell), apdo. 60.

6 Sobre esto, Ruffert (2015: 759).
} 
decisiones del $\mathrm{BCE}$ ) y la considera sin efectos ni carácter vinculante en Alemania. En una reacción inmediata (lo que, quizá, explica la posible exageración), por ejemplo, se califica esa decisión como (probablemente) «la más importante en los más de 70 años de historia» del BVerfG; y se llega a comparar su resolución del caso PSPP con la infame sentencia Dred $S \operatorname{cott}^{7}$ del Tribunal Supremo de los Estados Unidos ${ }^{8}$, desde luego, no situada en el distinguido plano de las matizadas disquisiciones necesarias para distinguir la política monetaria de la política económica.

Creo que conviene plantear en este momento de forma general cuáles son las cuestiones que están aquí en juego, antes de pasar a su análisis pormenorizado más adelante. Para el título de este comentario he escogido tres términos: democracia, metodología y dinero, que me parece que sirven también para llevar a cabo esta primera aproximación a la decisión del BVerfG.

El problema fáctico desencadenante de los problemas jurídicos se puede reconducir al concepto «dinero». El PSPP se aprobó como una medida de política monetaria del $\mathrm{BCE}$, con la intención de mantener la inflación algo por debajo del $2 \%$, pero el simple anuncio de la compra de deuda pública por parte de los bancos centrales tiene importantes efectos secundarios de tipo económico y fiscal: como todos los operadores en el mercado saben que pueden vender la deuda pública a esos bancos en el mercado secundario, sube la demanda de esos títulos y bajan los tipos de interés y lo que deben pagar los Estados por las nuevas emisiones de deuda. Los Estados encuentran más dinero para financiarse en condiciones favorables. A corto o medio plazo, además, mejora la situación económica, por ejemplo, de los bancos comerciales titulares de ese tipo de valores con riesgo; se altera la rentabilidad de los planes de pensiones; se incrementa también el riesgo de burbujas inmobiliarias; empresas poco competitivas pueden mantenerse en el mercado, porque los bajos tipos de interés les facilitan la refinanciación, etc. ${ }^{9}$ Dicho de forma sintética y tosca, pero gráfica: el auxilio del $\mathrm{BCE}$ a la prima de riesgo de los perezosos países del sur «expropia» al ahorrador alemán ${ }^{10}$.

La cuestión es, entonces, si esas consecuencias pueden calificarse de indirectas, cuando los efectos sobre las políticas económicas son pretendidos o aceptados conscientemente; y a esos efectos corresponde, además, un peso

Dred Scott v. Sandford, 60 U. S. (19 How.) 393 (1857).

Así, Sarmiento (2020: 9).

9 Estos efectos se describen en la Sentencia del BVerfG (Segundo Senado) de 5 de mayo de 2020 (caso PSPP), apdos. 170-175.

10 La expresión, con la misma intención gráfica, en Ruffert (2020: 3). 
equiparable al de la finalidad puramente monetaria ${ }^{11}$. En términos competenciales esto plantea si el BCE está manteniéndose con el PSPP en el ámbito de su competencia monetaria (art. 127.1 TFUE), o se está extralimitando para invadir el espacio de la política económica y fiscal que pertenece a los Estados miembros.

Con esto ya se llega a la «democracia». Porque hablar de reparto de competencias entre la Unión Europea y los Estados miembros en el derecho público alemán significa inevitablemente hablar de democracia en Alemania, por los rigurosos y sofisticados contornos que el desarrollo dogmático del principio democrático tiene en ese derecho: que los órganos de la Unión Europea respeten escrupulosamente los límites del poder que los Estados les han atribuido en los tratados es una exigencia del principio democrático en Alemania. Que la Unión Europea — permítase la expresión- «robe» competencias a Alemania significa que también le «roba» democracia. El recorte en el nivel de legitimidad democrática del poder público ejercido por la Unión Europea, en Alemania, no solo afecta a principios fundamentales objetivos de la Grundgesetz (art. 20 GG), sino también a un derecho fundamental de los ciudadanos alemanes a su autodeterminación democrática (art. 38.1 GG), cuyo contenido tiene un alcance desconocido, por ejemplo, en España. De ahí la importancia del respeto a los fundamentos competenciales de la Unión Europea; y aquí, en concreto, a la delimitación entre política monetaria y política económica y fiscal ${ }^{12}$. El control del ultra vires europeo es una herramienta al servicio de la preservación de la democracia alemana.

Y el tercer concepto que figura en el título de este comentario, la «metodología», aparece porque para constatar el ultra vires europeo (el del BCE y el del TJ) el BVerfG utiliza fundamentalmente el instrumento del principio de proporcionalidad, que ocupa un puesto destacado en los estudios modernos de la metodología del derecho.

\section{EL PROCESO Y LAS DECLARACIONES DE LA SENTENCIA}

En el proceso sobre el PSPP se acumularon cuatro recursos de amparo, en los que un total de más de 1700 ciudadanos que invocan su derecho

11 Así lo planteó el BVerfG al formular su cuestión prejudicial ante el TJ; véase la Sentencia del BVerfG (Segundo Senado) de 5 de mayo de 2020 (caso PSPP), apdo. 135.

12 Sentencia del BVerfG (Segundo Senado) de 5 de mayo de 2020 (caso PSPP), apdos. 158-159. 
individual a la autodeterminación democrática (art. 38.1 GG) se dirigen indirectamente contra las decisiones del Banco Central Europeo (adoptadas de 2015 a 2017) que aprobaron y modificaron posteriormente el PSPP, y directamente contra una omisión del Gobierno y el Parlamento federales, que permitieron que el mencionado programa de compra de deuda pública se llevara a cabo sin que el BCE hubiera justificado que el PSPP cumplía con las exigencias del principio de proporcionalidad.

La sentencia se adopta por siete votos contra uno ${ }^{13}$. Después de inadmitir algunas de las cuestiones planteadas por los recurrentes en amparo por enderezar la impugnación directamente contra actos de la Unión Europea y no de órganos estatales alemanes (que son los únicos sobre los que ejerce su jurisdicción el BVerfG) (apdo. 93), las demandas se estiman parcialmente.

El Gobierno y el Parlamento federales han vulnerado el derecho de los recurrentes a la autodeterminación democrática (art. 38.1 GG) por no adoptar medidas adecuadas contra las decisiones del BCE relativas al PSPP, que no han sido examinadas ni justificadas por dicho órgano conforme a las exigencias del principio de proporcionalidad (apdo. 116). Esas decisiones del BCE y la STJ (Gran Sala) de 11 de diciembre de 2018 (Weiss, asunto C-493/17), cuya interpretación de los tratados se califica como «absolutamente incompresible y, por eso, objetivamente arbitraria» (apdo. 118), se declaran como actos ultra vires y, por tanto, no aplicables ni vinculantes en Alemania (apdo. 234). Al Gobierno y al Parlamento federales, en virtud de su denominada «responsabilidad en la integración (europea)», se les impone la obligación de hacer todo lo posible para que el BCE realice el examen y la justificación de la proporcionalidad del PSPP (lo que no se considera incompatible con el respeto a la independencia de ese órgano europeo [art. 130 TFUE]) (apdo. 232). Y al Bundesbank se le prohíbe participar en el futuro en la ejecución de las decisiones relativas al PSPP, salvo que en el plazo transitorio de tres meses (hasta el 5 de agosto de 2020) el BCE, en una nueva decisión, justifique de forma comprensible que los objetivos de política monetaria pretendidos con el PSPP son ponderados en relación con sus consecuencias en materia de política económica y fiscal (apdo. 235).

En lo demás, las demandas de amparo se desestiman. El BVerfG acepta, aunque con reparos (como se verá), la respuesta a su cuestión prejudicial otorgada por la STJ en el asunto Weiss relativa a si el PSPP vulnera la prohibición de las ayudas financieras a los Estados miembros (art. 123 TFUE) ${ }^{14}$; y a si el

13 Como el magistrado discrepante no formula voto particular, no es posible saber de quién se trata. Lo explica Mayer (2020: 1120).

14 STJ (Gran Sala) de 11 de diciembre de 2018 (Weiss, asunto C-493/17), apdos. 101-158. 
reparto del riesgo de pérdidas podía afectar a la identidad constitucional alemana por comprometer la competencia presupuestaria del Parlamento federal, cuestión esta que fue inadmitida, por considerarse meramente hipotética, por la STJ Weiss ${ }^{15}$.

\section{LAS REACCIONES INMEDIATAS}

«Hasta ahora el BVerfG solo había amenazado; ahora los ladridos han cesado y Karlsruhe ha mordido ${ }^{16}$. La dureza de la crítica académica con la resolución constitucional alemana sobre el PSPP ha sido, en términos generales, directamente proporcional a la insólita audacia de la decisión adoptada por el $\mathrm{BVerfG}^{17}$. Estos argumentos se desglosarán más adelante.

En el plano de la política europea, el 10 de mayo de 2020 la presidenta de la Comisión, Ursula von der Leyen, emitió una nota de prensa en la que manifestaba que la Comisión consideraría la posibilidad de incoar un procedimiento por incumplimiento (art. 258 TFUE) contra Alemania. Sobre esa opción se pronunciaron concretamente los comentaristas de la sentencia ${ }^{18}$. La decisión de la iniciación de ese procedimiento es discrecional para la Comisión y para justificarla pueden utilizarse criterios jurídicos o políticos. Dar el paso supondría la necesidad de justificar por qué se actúa ahora contra Alemania, después de no haberlo hecho contra otros dos casos claros de desobediencia de altos tribunales nacionales a sendas decisiones del TJ: el Tribunal Constitucional checo declaró por Sentencia de 31 de enero de 2012 (caso Slovak Pensions) que era ultra vires la STJ de 22 de junio de 2011 (Landtová, asunto C-399/09), y el Tribunal Supremo danés decidió en su Sentencia de 6 de diciembre de 2016 (caso Ajos) ignorar la STJ (Gran Sala) de 19 de abril de 2016 (Dansk Industri, C-441/14) ${ }^{19}$. Por otra parte, parece conveniente ponderar la oportunidad política de poner al Gobierno y al Parlamento

15 STJ (Gran Sala) de 11 de diciembre de 2018 (Weiss, asunto C-493/17), apdos. 159-167.

16 Así, Ulrich Haltern (2020: 818).

17 En el material que yo he utilizado, expuesto en la bibliografía, en términos generales, solo puede distinguirse entre críticas más o menos contundentes. Quizá los comentarios más favorables a la sentencia del BVerfG (aunque también contengan opiniones discrepantes) sean los de Grimm (2020), Haltern (2020) y Ludwigs (2020).

18 Véanse, por ejemplo, Pernice (2020) y Möllers (2020), ambos accesibles online en verfassungsblog.de, de 16 de mayo de 2020.

19 Sucintas referencias a estos casos, por ejemplo, en Sarmiento (2020: 13) y Haltern (2020: 818). 
federales y al Bundesbank en la tesitura formal de tener que elegir entre la obediencia al BVerfG o la vinculación a las decisiones del TJ.

La reacción del BCE ha estado marcada por el pragmatismo. Por una parte, decide ampliar la cuantía del Pandemic Emergency Purchase Programme $(\mathrm{PEPP})^{20}$ — sobre el que se volverá más adelante-, como gesto significativo de su independencia frente a las decisiones del BVerfG; pero, por otra, anuncia a través de su presidenta, Christine Lagarde, ante el Parlamento Europeo que el BCE apoyará al Bundesbank para dar respuesta a la exigencia de examen y justificación de las decisiones relativas al PSPP desde la perspectiva del principio de proporcionalidad demandada por el BVerfG.

El Consejo del BCE, en diversas reuniones sobre política monetaria celebradas en junio de 2020, deliberó y adoptó una nueva decisión relativa al PSPP en la que se contenían esas consideraciones relativas a la ponderación de los efectos económicos de sus decisiones monetarias; y permitió que el Bundesbank diera traslado de diversos documentos con información al respecto al Gobierno y al Parlamento federales. Seguidamente, ambos órganos constitucionales, con más de un mes de antelación con respecto al plazo de tres meses concedido por la sentencia del BVerfG (que, como se ha dicho, expiraba el 5 de agosto de 2020), resolvieron que la justificación procedente del BCE cumplimentaba adecuadamente los requisitos de motivación exigidos por la sentencia del BVerfG, por lo que el Bundesbank podía seguir participando en el PSPP ${ }^{21}$.

Si la situación quedara en ese punto, en realidad, ya no podría hablarse de un incumplimiento por parte de Alemania del derecho de la Unión Europea. A pesar de la gravedad del conflicto entre los dos tribunales y del duro lenguaje utilizado por la sentencia del BVerfG contra la decisión del TJ en el caso Weiss, si la sentencia alemana deja de producir efectos contrarios al derecho de la Unión Europea, no podría hablarse ya de un incumplimiento de este por parte de Alemania ${ }^{22}$. Aquí habría terminado el incidente a efectos prácticos, aunque es obvio que de la doctrina establecida en esta sentencia del BVerfG se seguirá discutiendo en el futuro.

20 Sobre él no se pronuncia la sentencia comentada del BVerfG, pero no ha pasado inadvertido — como se dirá — que este programa, que forma parte de la respuesta europea frente a la crisis del coronavirus, se separa de varios de los criterios que establece el BVerfG en su enjuiciamiento relativo a la prohibición de ayudas financieras a los Estados miembros (art. 123 TFUE).

21 Esta información, en la página web del Deutscher Bundestag (Drucksache 19/20621), y en el Frankfurter Allgemeine Zeitung de 3 de agosto de 2020: «EZB-Ulteil: Weidmann sieht Forderungen des Verfassungsgerichts als erfüllt an».

22 Así, Poiares Maduro (2020). 
En mi opinión, en una primera aproximación general, la fundamentación de la sentencia comentada del BVerfG no es tan sólida como la extraordinaria contundencia del golpe asestado hubiera exigido. Con esto adelanto la estructura de la exposición que sigue. No creo que haya nada que reprochar, en abstracto, a los presupuestos relativos a la teoría del Estado (que aluden a la naturaleza de la Unión Europea) y, derivadas de aquellos, a las reservas formuladas por el BVerfG en relación con la primacía del derecho de la Unión Europea. Tampoco considero criticable la finalidad de fondo del BVerfG de evitar que en la Unión Europea el desarrollo de los procesos político-democráticos para solucionar el problema de la ruptura entre el norte y el sur de la eurozona se sustituya por la actuación, cuando esos procesos no han tenido lugar o han fracasado, de órganos independientes, como el BCE, con un bajísimo nivel de legitimidad democrática.

Por otra parte, sin embargo, la construcción por el BVerfG del recurso de amparo para la defensa del derecho a la autodeterminación democrática que tiene como objeto (aunque sea indirecto) actos de órganos de la Unión Europea supuestamente ultra vires puede calificarse, con la mejor de las voluntades, como una peculiaridad del derecho constitucional alemán. Y, por último, el concreto enjuiciamiento, con el auxilio del instrumento metodológico del principio de proporcionalidad, de las decisiones del BCE y de la STJ Weiss como actos ultra vires puede - a mi juicio- considerarse como lamentablemente incorrecto. Basta, por lo pronto, con caer en la cuenta de que las decisiones del BCE se han calificado como "evidentemente» contrarias a los límites de sus competencias por un defecto de motivación: la falta de examen de esas decisiones desde la perspectiva del principio de proporcionalidad y la exposición de los resultados de ese examen. Por eso se exige que el BCE realice a posteriori ese examen y esa justificación. Con independencia de que ahora se consideren convincentes o no los argumentos del BCE, la conclusión solo puede ser que, en su momento, sus decisiones fueron, como máximo, «posiblemente» ultra vires (la falta de motivación impedía hacer un juicio definitivo), pero no, desde luego, «evidentemente» ultra vires. Sobre esto se volverá más adelante.

\section{TRES PRESUPUESTOS DE DERECHO CONSTITUCIONAL Y PROCESAL}

\section{TEORÍA DEL ESTADO Y RESERVAS ALEMANAS A LA PRIMACÍA DEL DERECHO DE LA UNIÓN EUROPEA}

La doctrina constitucional alemana sobre la naturaleza de la Unión Europea está construida sobre una teoría del Estado clásica (también alemana, 
pero que ha ejercido una notable influencia en el derecho público de otros países del continente europeo, entre ellos, en el español): la Unión Europea es una organización de derecho internacional público creada a través de tratados internacionales. Representa un modelo de desarrollo realmente único en el contexto del derecho de las organizaciones internacionales, pero nunca hasta ahora ha subido al escalón, conceptualmente distinto, del Estado federal. El término «supranacionalidad» que la doctrina académica utiliza con frecuencia para referirse a la Unión Europea —en contraposición a la mera «internacionalidad»- no constituye un concepto definido y distinto de la teoría del Estado, sino una mera categoría descriptiva de unas características (poder normativo propio, efecto directo y primacía de su derecho, posibilidad de decisiones adoptadas por mayoría, existencia de órganos independientes, etc.) que, en tal intensidad y combinación, solo se dan en aquella ${ }^{23}$.

Desde su sentencia sobre el tratado de Maastricht el BVerfG utiliza el término «Unión de Estados» (Staatenverbund) ${ }^{24}$, no como una expresión cualitativamente nueva de la teoría del Estado o del derecho internacional público, sino como un concepto que describe un sistema organizativo único, en el marco del derecho internacional, en cuanto a su alto grado de integración. Determinante para el BVerfG es que la soberanía sigue siendo un atributo de los Estados miembros, lo que significa tanto como que no puede entregarse a la Unión Europea el poder de decidir sobre el alcance de sus competencias, ni el de crear competencias propias nuevas. Según la teoría del Estado alemana clásica, esta competencia de decidir sobre la propia competencia (Kompetenz-Kompetenz) pertenece como atributo definitorio al poder soberano ${ }^{25}$; es el «santo grial de la estatalidad $»^{26}$.

Para aumentar sus poderes la Unión Europea necesita de la actuación de los Estados miembros, que siguen siendo los «dueños» o «señores» de los tratados. No puede sorprender en este contexto el valor argumentativo que la jurisprudencia del BVerfG (y también la sentencia que ahora se comenta) ha otorgado al principio de la competencia de atribución (art. 5.1 TUE), definitorio del poder que los Estados miembros han entregado a la Unión (Streinz, 2019: 53). Desde el punto de vista del principio democrático, esta construcción se completa con la idea de que la legitimidad democrática de la Unión Europea descansa, sobre todo, en los Parlamentos nacionales; aunque esta

\footnotetext{
23 Sobre esto, por todos, Rudolf Streinz (2019: 49-54).

24 Sentencia del BVerfG (Segundo Senado) de 12 de octubre de 1993 (caso Maastricht), apdos. 90, 94, 95, passim.

25 Véase, por ejemplo, Jellinek (2000: 449-450).

26 La gráfica expresión, en Sauer (2020: 5).
} 
línea legitimadora se complemente con la vía dual prevista en el art. 10.2 TUE: representación de los ciudadanos en el Parlamento Europeo y de los Estados miembros en el Consejo a través de sus Gobiernos, por su parte, democráticamente responsables. El «cambio de sistema» de lo que es ahora la Unión Europea a un Estado federal europeo ni siquiera estaría cubierto por la redacción actual del art. 23 GG (el precepto que regula las cuestiones relativas a la Unión Europea) y no podría llevarse a cabo a través de una ley de reforma constitucional conforme a lo que prevé la Grundgesetz, sino que requeriría la aprobación de una nueva Constitución como resultado del ejercicio del poder soberano por el pueblo alemán (art. 146 GG) ${ }^{27}$. A mi juicio, de la teoría del Estado que está detrás de esta concepción de la Unión Europea puede decirse que es clásica, pero no que sea provinciana ${ }^{28}$.

Con esto se llega a la primacía del derecho de la Unión Europea y sus (posibles) límites. La jurisprudencia del TJ fundamenta esa primacía — en principio, absoluta - en la misma naturaleza de ese derecho (un «nuevo ordenamiento de derecho internacional $»^{29}$, o un «ordenamiento jurídico propio») ${ }^{30}$, que necesita esencialmente ser aplicado de manera uniforme en todos los Estados miembros. En la jurisprudencia del BVerfG, por el contrario, la primacía del derecho de la Unión Europea encuentra su fundamento en la Grundgesetz, que autoriza esa primacía. Esta diferencia de partida tiene consecuencias importantes. Si el fundamento de la primacía se encuentra en la Constitución nacional, la primacía solo llega hasta donde alcance la posibilidad de su autorización en esa Constitución. Los límites a esa autorización pueden proceder de preceptos constitucionales expresos o de la interpretación constitucional. La peculiaridad alemana en este punto consiste en el precepto constitucional que contiene la determinada «cláusula de eternidad», el art. 79.3 GG: lo que la propia Grundgesetz identifica como inmodificable por la vía de la ley de reforma constitucional (los principios del Estado federal y del Estado social y democrático de derecho...) necesariamente constituye un límite a la transferencia de poder derivado de la Constitución a la Unión Europea y a la primacía del derecho de esta. Y el BVerfG se ha reconocido la competencia de controlar que esos límites se respetan por parte de los órganos de la Unión Europea.

La primacía del derecho de la Unión Europea, en definitiva, conforme a la tesis del BVerfG, no es absoluta en Alemania (como, por otra parte, sucede

27 Sentencia del BVerfG (Segundo Senado) de 30 de junio de 2009 (caso Tratado de Lisboa), apdo. 362 .

28 Así ("parochial theory of the State forms»), sin embargo, Sauer (2020: 5).

29 STJ de 5 de febrero de 1963 (Van Gend \& Loos, asunto 26/62).

30 Así, ya, STJ de 15 de julio de 1964 (Costa/ENEL, asunto 6/64). 
en otros Estados miembros), sino que se mueve dentro de unos límites cuya observancia controla el Alto Tribunal alemán. Por supuesto, esta concepción no coincide con la del TJ, que no puede reconocer límites a la primacía del derecho de la Unión como consecuencia del punto de partida de su jurisprudencia, conforme al cual es el propio derecho de la Unión Europea (no las constituciones nacionales) el que determina la relación de sus normas con la de los ordenamientos jurídicos de los Estados miembros. Pero, desde luego, no es posible sorprenderse ahora de que algunos tribunales superiores o constitucionales nacionales establezcan "reservas» a dicha primacía para casos extremos y con estrictos requisitos de apreciación ${ }^{31}$. Es posible criticar la concreta forma en que se ha llevado a cabo el control a través de una de esas reservas (aquí va a hacerse), pero no manifestar a estas alturas extrańeza por la existencia, en general, de esas «reservas».

Es suficientemente conocido que la jurisprudencia del BVerfG ha desarrollado tres supuestos de reservas a la primacía del derecho de la Unión Europea, que autorizan (y obligan) a ese tribunal a examinar actos nacionales de transposición o ejecución del derecho de la Unión (nunca, directamente, actos de la Unión Europea) conforme a criterios derivados de la Grundgesetz: la que se refiere al control del nivel de protección de derechos fundamentales, la que responde a la extralimitación «evidente y estructuralmente relevante» en el ejercicio de competencias por parte de órganos de la Unión Europea (ultra vires) y la que se basa en la salvaguarda de la identidad constitucional alemana ${ }^{32}$. Siempre ha sido imprecisa la relación de esas tres reservas entre ellas. En la Sentencia del BVerfG (Segundo Senado) de 21 de junio de 2016 (caso $O M T$ ), por ejemplo, el tribunal alemán pareció reconducir el ultra vires y la identidad constitucional a un fundamento dogmático único. En la sentencia sobre el PSPP — como se verá- el BVerfG se ha separado de ese camino y ha aplicado el control sobre el acto ultra vires con desconexión completa con respecto a la identidad nacional ${ }^{33}$. En términos generales, por cierto, el supuesto de reserva que parece menos cuestionado como límite a la primacía aplicativa del derecho de la Unión Europea es el que se refiere a la salvaguarda de la identidad constitucional ${ }^{34}$, por el fuerte carácter simbólico (además del estrictamente jurídico) de la «cláusula de eternidad» del art. 79.3

\footnotetext{
31 En sentido parecido, Haltern (2020: 818), Nettesheim (2020: 1632), Callies (2020: 900).

32 Sobre esto, Streinz (2019: 80-96).

33 Sobre esto, Callies (2020: 900-901).

34 Véanse, por ejemplo, Callies (2020: 902) y Ludwigs (2020: 6-7).
} 
GG; y por su mención, como límite de obligatorio respeto por parte de la Unión, en el art. 4.2 TUE.

El BVerfG resume en la sentencia comentada sobre el PSPP del siguiente modo las tesis que acaban de exponerse y el uso que está dispuesto a hacer de la reserva del ultra vires: que en los casos límite de posibles excesos competenciales por parte de los órganos de la Unión Europea puedan existir diferencias de enjuiciamiento desde las perspectivas de la Constitución nacional y del derecho de la Unión Europea se debe a la circunstancia de que los Estados miembros siguen siendo, también después de la entrada en vigor del Tratado de Lisboa, dueños o señores de los tratados y a que no se dio con aquel el paso hacia un Estado federal. Las inevitables tensiones que derivan de esta construcción deben solucionarse de forma cooperativa, como exige la idea europea de integración, y a través del ejercicio de la consideración recíproca ${ }^{35}$.

Creo que merece la pena terminar este apartado con un apunte de derecho comparado. Para el Tribunal Constitucional español también es la Constitución española el fundamento de la primacía del derecho de la Unión: es la propia Constitución la que ha dispuesto un régimen de aplicación que otorga «preferencia aplicativa a normas de otro ordenamiento diferente del nacional»; «la Constitución ha aceptado, ella misma, en virtud de su art. 93, la primacía del derecho de la Unión en el ámbito que a ese derecho le es propio ${ }^{36}$. Sin embargo, ninguna reserva expresa ha formulado nuestro Alto Tribunal en relación con la observancia por parte de la Unión de los límites de ese ámbito que «le es propio». Parece que la respuesta del Estado español a una deriva del derecho de la Unión Europea incompatible con la Constitución española solo puede ser la reforma constitucional o el abandono de la Unión Europea ${ }^{37}$. En mi opinión, desde el punto de vista de la construcción conjunta de la comunidad jurídica en que consiste la Unión Europea no es necesariamente mejor la cómoda ausencia espańola de reservas que el ejercicio responsable y cooperativo de ásperas reservas a la primacía (como las formuladas por el BVerfG), que, sin embargo, permiten el debate eficaz y el control recíproco entre altas instancias judiciales en relación con cuestiones constitucionales relevantes ${ }^{38}$. Hay que reconocer, no obstante, que esto no es - a mi juiciolo que ha sucedido, en concreto, en el caso del PSPP.

35 Sentencia del BVerfG (Segundo Senado) de 5 de mayo de 2020 (caso PSPP), apdo. 111 .

36 DTC 1/2004, de 13 de diciembre (sobre el Tratado por el que se establece una Constitución para Europa), FJ 4.

37 Ibid.

38 En sentido parecido, Roca (2020: 2853). 


\section{EL DERECHO FUNDAMENTAL A LA AUTODETERMINACIÓN DEMOCRÁTICA}

Quizá el aspecto más difícilmente comprensible para el lector no alemán que se acerca por primera vez a esta decisión del BVerfG es el de la construcción y el alcance en Alemania del derecho fundamental «a la democracia» $\mathbf{o}$ «a la autodeterminación democrática», que se deriva del derecho de sufragio activo garantizado en el art. 38.1 GG. Que del derecho al voto en las elecciones al Parlamento federal se llegue a una pretensión iusfundamental que autoriza y obliga al BVerfG a examinar decisiones del BCE y del TJ desde la perspectiva del ultra vires no es algo fácil de entender para el jurista español (ni, seguramente, de otros países europeos).

La argumentación que lleva de un punto a otro empieza con la dignidad de la persona (nada menos) y termina con la defensa que el citado precepto constitucional dispensa frente a las modificaciones estructurales del derecho de la organización estatal como consecuencia de la transferencia de poderes soberanos a la Unión Europea o de su ejercicio ultra vires por parte de los órganos de aquella: la Grundgesetz parte de la dignidad del individuo libre que incluye el derecho del ciudadano a influir, a través de elecciones y referendos, en libertad e igualdad, en el poder público que le afecta; el individuo tiene que poder participar de forma responsable en la mayor medida posible en las decisiones públicas que afectan a todos; el derecho de sufragio activo protege, así, tanto frente a la pérdida sustancial de poder del Parlamento como frente al ejercicio de competencias por órganos con un injustificadamente bajo nivel de legitimidad democrática ${ }^{39}$. Es difícil encontrar un mejor ejemplo de subjetivación iusfundamental del contenido de un principio de derecho objetivo, como es el principio democrático ${ }^{40}$.

Conforme a la exposición de la sentencia comentada: el derecho de sufragio activo (art. 38.1 GG) no se limita a posibilitar con las elecciones la legitimidad formal del poder público ejercido por la Federación, sino que tiene también un contenido material e incluye la pretensión de los ciudadanos de someterse solo a un poder público en el que ellos puedan participar e influir, porque todo el poder público ejercido en Alemania debe poder ser reconducible al pueblo (art. $20.2 \mathrm{GG}{ }^{41}$. Este derecho fundamental a la autodeterminación democrática también rige en los asuntos relativos a la integra-

39 Así, en síntesis, por ejemplo, Sentencia del BVerfG (Segundo Senado) de 21 de junio de 2016 (caso OMT), apdos. 124-126.

40 De forma parecida, Sauer (2020: 3-4).

41 Sentencia del BVerfG (Segundo Senado) de 5 de mayo de 2020 (caso PSPP), apdo. 99. 
ción europea, de tal manera que la forma y la medida de la transferencia de competencias soberanas a la Unión (conforme a lo previsto en el art. 23 GG, el equivalente a nuestro art. $93 \mathrm{CE}$, pero con una densidad regulativa bastante mayor) también debe responder a principios democráticos que imponen que el poder configurador del Parlamento federal, en especial, su competencia presupuestaria, debe preservarse sustancialmente ${ }^{42}$.

La conexión entre el ultra vires por parte de un órgano de la Unión Europea y el derecho a la autodeterminación democrática del ciudadano alemán se hace ya evidente: cuando ese órgano de la Unión se atribuye a sí mismo y ejerce competencias que no le han sido transferidas, se ve afectado el proceso decisorio democrático y la reconducibilidad al pueblo del ejercicio del poder público conforme a lo dispuesto por el derecho alemán de organización.

\section{EL RECURSO DE AMPARO PARA LA DEFENSA DEL DERECHO FUNDAMENTAL A LA DEMOCRACIA EN CUESTIONES RELATIVAS A LA INTEGRACIÓN EUROPEA}

Más sofisticada todavía que el desarrollo del contenido sustantivo del derecho fundamental a la autodeterminación democrática es la articulación de la vía procesal de defensa de ese derecho a través del recurso de amparo ante el BVerfG en asuntos relativos a la integración europea. En concreto, se ceñirá la exposición en este apartado al recurso de amparo formulado con ocasión de un reproche de ultra vires con respecto a una actuación de un órgano de la Unión Europea, que es la estructura de la acción procesal ejercitada ante el BVerfG en el caso que se comenta del PSPP.

Es conocido que la tendencia general con respecto a la admisibilidad del recurso de amparo ha sido en las últimas décadas la de establecer requisitos adicionales para limitar la entrada de asuntos en el BVerfG. El requisito del derecho español relativo a que el asunto sometido a la consideración del Tribunal Constitucional tenga una "especial transcendencia constitucional» (art. 50.1.b LOTC) había sido introducido ya anteriormente en el derecho alemán utilizando la expresión «relevancia constitucional fundamental» ( $\$$ 93.a de la Ley del BVerfG). No es esa, sin embargo, la tendencia que está mostrando el BVerfG en los asuntos en los que el derecho a la democracia (art. $38.1 \mathrm{GG})$ se invoca precisamente en el contexto de la integración europea ${ }^{43}$.

42 Sentencia del BVerfG (Segundo Senado) de 5 de mayo de 2020 (caso PSPP), apdo. 101.

43 Así, voto particular de la magistrada Lübbe-Wolff a la decisión del BVerfG (Segundo Senado) de 14 de enero de 2014 de plantear cuestión prejudicial ante el TJ en el caso OMT, apdo. 14 . 
En esta materia el acceso al recurso de amparo se ha abierto con tanta amplitud como se abren «las puertas de un granero» ${ }^{44}$, porque el BVerfG ha construido, paso a paso, una "acción popular» ${ }^{45}$ contra el ultra vires de la Unión Europea; y porque, además, los criterios que delimitan el concepto de ultra vires (evidencia y relevancia estructural) son tan imprecisos que malamente pueden cumplir la función de canalizar con rigor la entrada de asuntos en el tribunal ${ }^{46}$. Téngase en cuenta, por otra parte, que el objeto del recurso de amparo difícilmente caerá bajo la competencia de ningún otro órgano judicial alemán, por lo que el recurrente se presenta directamente en el BVerfG con su demanda de amparo, en principio, sin agotar ninguna vía judicial previa.

Con ello, la competencia del BVerfG en la resolución de los recursos de amparo se desvincula de la necesidad subjetiva de protección individual (que es típica de ese recurso) para el restablecimiento de una libertad del ciudadano (Callies, 2020: 899). En el caso del PSPP que nos ocupa, por ejemplo, parece claro que cualquier ciudadano alemán puede dirigir a las decisiones monetarias del BCE la misma queja que los recurrentes en amparo relativa a que aquellas tienen efectos sensibles sobre la situación económica en Alemania (Möllers, 2020: 1/4). Por otra parte, con este recurso de amparo contra el ultra vires de la Unión Europea se crea, de hecho, un recurso individual ante el BVerfG contra actos jurídicos de la Unión (aunque estos sean examinados por aquel indirectamente) que abre la posibilidad de injerencias (al menos, también, indirectas) en la competencia de enjuiciar la validez de los actos de la Unión Europea atribuida al TJ conforme al art. 263 TFUE (Pernice, 2020: 3/8).

Según la jurisprudencia del BVerfG, son destinatarios obligados por el derecho fundamental a la democracia en los asuntos relativos a la integración europea los órganos constitucionales a los que la Grundgesetz impone (art. 23 GG) la responsabilidad de vigilancia del mantenimiento del programa de la integración (europea), en especial, el Gobierno y el Parlamento federales ${ }^{47}$. Obviamente, esto implica que no son objeto directo de la impugnación a través del recurso de amparo las decisiones del BCE y la sentencia del TJ Weiss, sino las omisiones de esos dos órganos constitucionales, que no reaccio-

44 Así, crítico, Haltern (2020: 820).

45 Utilizan la expresión el voto particular del magistrado Gerhardt a la decisión del BVerfG (Segundo Senado) de 14 de enero de 2014 de plantear cuestión prejudicial ante el TJ en el caso OMT, apdo. 7; y Callies (2020: 899).

46 Voto particular del magistrado Gerhardt a la decisión del BVerfG (Segundo Senado) de 14 de enero de 2014 de plantear cuestión prejudicial ante el TJ en el caso OMT, apdo. 7.

47 Sentencia del BVerfG (Segundo Senado) de 5 de mayo de 2020 (caso PSPP), apdos. 106-107. 
naron frente a la actuación ultra vires de los órganos de la Unión. El Gobierno y el Parlamento federales tienen una obligación objetiva (que se corresponde con el derecho subjetivo del ciudadano) de reacción frente al ultra vires, que deriva de la responsabilidad sobre la integración que les compete ${ }^{48}$. Ya se ha dicho que, de hecho, algunas de las cuestiones planteadas por los recurrentes en amparo fueron inadmitidas por formular la impugnación directamente contra actos de la Unión Europea y no de órganos estatales alemanes, que son los únicos sobre los que ejerce su jurisdicción el BVerfG ${ }^{49}$.

Que el recurso de amparo se dirija frente a omisiones de órganos constitucionales plantea dos problemas distintos, aunque relacionados entre sí. Por una parte, la jurisprudencia del BVerfG ha establecido que las omisiones del Parlamento o del Gobierno federales solo pueden impugnarse a través del recurso de amparo cuando el recurrente puede invocar un mandato expreso de la Grundgesetz que delimite en lo esencial el contenido y el alcance de la obligación de actuar que se considera vulnerada. Pues bien, parece claro que ese mandato expreso no existe en el caso del recurso de amparo dirigido frente al ultra vires de la Unión ${ }^{50}$.

En segundo lugar, se sitúa el problema de determinar lo que, en concreto, el derecho fundamental exige de la actuación del Gobierno y el Parlamento federales: cuál será, en caso de éxito del recurso de amparo, la condena que se imponga al Gobierno y al Parlamento para dar satisfacción a la pretensión del recurrente. Como el propio BVerfG reconoce en la sentencia comentada, el Gobierno y el Parlamento federales tienen un amplio margen de actuación en la adopción de las medidas (políticas o jurídicas) adecuadas contra la actuación ultra vires de un órgano de la Unión Europea ${ }^{51}$.

El Gobierno puede, por ejemplo, decidir interponer un recurso frente al acto ultra vires ante el TJ, como también es posible que en el Parlamento se formulen preguntas al Gobierno al respecto o, incluso, se utilice el argumento de la omisión del Ejecutivo para plantear una moción de censura. Eso, entre otras muchas respuestas, sobre todo, de tipo político. El BVerfG carece de criterios jurídicos para imponer al Gobierno y al Parlamento obligaciones de actuación positiva en respuesta al ultra vires invocado en el amparo ${ }^{52}$. La cuestión

48 Sentencia del BVerfG (Segundo Senado) de 21 de junio de 2016 (caso OMT), apdo. 83.

49 Sentencia del BVerfG (Segundo Senado) de 5 de mayo de 2020 (caso PSPP), apdo. 93.

50 Así, voto particular de la magistrada Lübbe-Wolff a la decisión del BVerfG (Segundo Senado) de 14 de enero de 2014 de plantear cuestión prejudicial ante el TJ en el caso OMT, apdo. 18, con referencias jurisprudenciales. También lo destaca Callies (2020: 899).

51 Sentencia del BVerfG (Segundo Senado) de 5 de mayo de 2020 (caso PSPP), apdo. 109.

52 Lo destacan, en tono crítico con la jurisprudencia creada por las sentencias del BVerfG en los casos OMT y PSPP, Callies (2020: 898) y Ruffert (2017: 1231). 
relativa a cómo esos órganos constitucionales deben responder a la extralimitación competencial de la Unión es una cuestión de discrecionalidad política que debe sustanciarse a través del proceso democrático ${ }^{53}$. Que el ciudadano pueda dirigir en un determinado sentido, por ejemplo, la fijación del orden del día del Parlamento federal con ayuda del BVerfG no puede explicarse en el marco de las reglas constitucionales relativas al trabajo parlamentario ${ }^{54}$.

Es posible descubrir detrás de esta forzada articulación del recurso de amparo para la defensa del derecho fundamental a la democracia frente al ultra vires de la Unión Europea una desconfianza del BVerfG en relación con la política europea del Parlamento federal ${ }^{55}$. Desde luego hay algo de ironía en esto: se discute de democracia y se sospecha de la actuación del órgano por excelencia de la representación democrática. Precisamente, la relativa fortaleza del Parlamento federal en lo tocante a los asuntos europeos no es el resultado de su propio activismo, ni de que ese órgano haya aprovechado su función de legislador para robustecer su posición en esa materia, sino (esto también es una ironía) de la feroz defensa del BVerfG del papel del Parlamento en la salvaguarda de la democracia representativa en el contexto de la integración europea ${ }^{56}$. A través de este recurso de amparo, sin embargo, parece que el BVerfG suplanta al Parlamento en su responsabilidad por la integración y se convierte él en el «custodio de la democracia» (no solo de la Constitución).

\section{DEMOCRACIA}

\section{EL ULTRA VIRES EUROPEO COMO «RECORTE» DE LA DEMOCRACIA ALEMANA}

El problema democrático que está en el centro de la sentencia del BVerfG sobre el PSPP, si se analizan las cosas con detenimiento, se sitúa en un doble plano. Por una parte, como ya se ha dicho, un eventual ejercicio ultra vires de competencias por parte de un órgano de la Unión Europea (con independencia

53 Voto particular de la magistrada Lübbe-Wolff a la decisión del BVerfG (Segundo Senado) de 14 de enero de 2014 de plantear cuestión prejudicial ante el TJ en el caso OMT, apdo. 12 .

54 Voto particular del magistrado Gerhardt a la decisión del BVerfG (Segundo Senado) de 14 de enero de 2014 de plantear cuestión prejudicial ante el TJ en el caso OMT, apdo. 21.

55 Así, Callies (2020: 899).

56 Sobre esto, Fromage (2020: 4). 
de cuál sea ese órgano) implica lógicamente que decisiones que deberían adoptarse por órganos nacionales alemanes, conforme a estructuras de legitimidad democrática estatal que reconducen al pueblo alemán (o al del Land correspondiente) el ejercicio del poder público, se adoptan por una autoridad de una organización supranacional. Pero, por otra parte, el «recorte» de la democracia también tiene una vertiente solo situada en el plano de la propia Unión Europea: «[...] el núcleo del problema democrático que ha ocupado al BVerfG es que la Unión Europea se valga de instituciones independientes para conseguir resultados de carácter altamente políticos» (Haltern, 2020: 820).

A la primera cuestión ya se ha hecho referencia. Bastará aquí con volver a expresarla en los mismos términos que la sentencia que se comenta: el principio de la competencia de atribución (art. 5.1 TUE) no es solo un principio del derecho de la Unión Europea, sino que conecta también con principios constitucionales de los Estados miembros. Constituye la justificación clave del recorte en el nivel de legitimidad democrática del poder público ejercido por la Unión Europea, que en Alemania no solo afecta a principios fundamentales objetivos de la Grundgesetz (art. 20 GG), sino también al derecho fundamental de los ciudadanos a su autodeterminación democrática (art. 38.1 GG). De ahí la importancia del respeto a los fundamentos competenciales de la Unión Europea y, en concreto, a la delimitación entre política monetaria y política económica y fiscal. La calificación de una medida como perteneciente a la política monetaria determina el nivel de legitimidad democrática y el control del ámbito político afectado, porque esa competencia está atribuida en la Unión a un órgano independiente ${ }^{57}$. A la segunda vertiente del problema se dedica el apartado siguiente.

\section{EL REPROCHE DE LA SUSTITUCIÓN DE LA POLÍTICA DEMOCRÁTICA EN LA UNIÓN EUROPEA POR LA ACTUACIÓN DE INSTITUCIONES INDEPENDIENTES}

La tensión dialéctica que los órganos independientes generan desde el punto de vista del principio democrático se resuelve normalmente explicando que una tarea pública solo puede desengancharse de las vías de control democrático cuando su ejercicio, por una parte, exige, por alguna razón justificada, independencia, y, por otra, no necesita de ninguna consideración de tipo político general y fundamental, sino que se dirige solo a la consecución de un fin

Sentencia del BVerfG (Segundo Senado) de 5 de mayo de 2020 (caso PSPP), apdos. 158-159. 
único y bien definido ${ }^{58}$. La interpretación estricta de las competencias de este tipo de órganos y la especial intensidad del control judicial sobre este aspecto son exigencias, también, del principio democráticos.

Lo que con frecuencia ha sucedido en la Unión Europea es que el bloqueo de los cauces políticos de adopción de decisiones ha sido compensado o sustituido por el activismo de las instituciones europeas independientes: la dogmática de la primacía del derecho comunitario y de su efecto directo se crea por el TJ cuando el proceso decisorio en el Consejo se paraliza a la sombra del derecho de veto; otro momento de bloqueo de la armonización legislativa en el Consejo tuvo su remedio sustitutorio en la jurisprudencia del TJ sobre el reconocimiento mutuo en el mercado interior ${ }^{60}$. Es innegable que, con referencia al activismo judicial del TJ, se explica bien la opinión relativa a que «el establecimiento de un tribunal supremo en una unidad política es un acto de repercusiones poco previsibles» ${ }^{61}$.

Más tarde, pero en la misma línea, el fracaso de los jefes de Estado o de Gobierno de los Estados miembros, que no llegaron a una solución global con la rapidez y el alcance necesarios para sacar a la eurozona del caos financiero en 2008, dio lugar a una actuación decisiva del $\mathrm{BCE}^{62}$, otro órgano independiente. Con el PSPP (entre otros programas) el BCE salió en auxilio del euro a través de una interpretación (como mínimo) flexible de su competencia en materia de estabilidad de precios, que indirectamente consigue bajar los costes de la financiación de algunos de los países de la eurozona. Mientras los procesos políticos para adoptar decisiones sobre la cesura entre los países del norte y del sur del euro estaban bloqueados, no puede extrañar que surja la sospecha de que el posible efecto secundario (bajar los costes de la financiación de algunos países de la zona euro) se había convertido, en realidad, en la finalidad fundamental de la medida nominalmente monetaria que el BCE adoptaba con el PSPP ${ }^{63}$. No me parece exagerado opinar en este contexto que, si se quiere atribuir al BCE el papel fundamental para la superación de las crisis del euro, sería necesario reformar los tratados ${ }^{64}$; y que son las posibles

58 Así, Haltern (2020: 821). Con aplicación específica al BCE, Feichtner (2020: 1093).

59 Sentencia del BVerfG (Segundo Senado) de 5 de mayo de 2020 (caso PSPP), apdo. 143.

60 Los dos ejemplos, en Haltern (2020: 820).

61 Así, con referencia al TJ y al Tribunal Supremo de los Estados Unidos, Wahl (2013: 152).

62 Así, Sarmiento (2020: 20).

63 Así, Haltern (2020: 823).

64 Así, Nettesheim (2020: 1632). 
diferencias entre la concepción de la democracia por el BVerfG y por el TJ las que conducen al núcleo del debate sobre el papel de las instituciones independientes en el derecho de la Unión ${ }^{65}$.

\section{METODOLOGÍA}

\section{EL PRINCIPIO DE PROPORCIONALIDAD Y LA DISTRIBUCIÓN DE COMPETENCIAS ENTRE LA UNIÓN EUROPEA Y LOS ESTADOS MIEMBROS}

El enjuiciamiento como ultra vires de las decisiones del BCE relativas al PSPP y de la sentencia del TJ en el caso Weiss lo realiza el BVerfG mediante el uso prácticamente exclusivo del principio de proporcionalidad como instrumento metodológico. Las decisiones del BCE no se consideran amparadas por su competencia en materia de política monetaria y de (mero) apoyo a la política económica de los Estados miembros (art. 127.1 TFUE) como consecuencia de la falta de consideración, en concreto, en el tercer escalón del juicio convencional de proporcionalidad (ponderación de inconvenientes y ventajas), de los efectos de la medida de política monetaria sobre la política económica de dichos Estados: mejora de las condiciones de refinanciación de estos, consecuencias económicas sobre los bancos, las empresas, los propietarios y los ahorradores, etc. (apdos. 164-177).

Por su parte, la sentencia Weiss del TJ atendería solo al fin perseguido (la consecución de una inflación por debajo pero cercana al $2 \%$ ) y a los medios empleados (la compra de deuda pública en los mercados secundarios) por la medida para considerar que esta se desarrolla en el ámbito de la política monetaria (apdo. 120). Pero esa sentencia del TJ no habría utilizado el principio de proporcionalidad con la función que le corresponde como correctivo en defensa de las competencias de los Estados miembros, para la delimitación entre la política monetaria y la política económica. Un examen conforme al principio de proporcionalidad no permitiría dejar fuera de consideración las consecuencias fácticas del PSPP sobre la economía, ni prescindir de una consideración valorativa global de las ventajas y los inconvenientes (apdos. 123, 127).

El BVerfG hace una exposición general del contenido del principio de proporcionalidad, del que dice que es un principio general del derecho de la Unión, codificado en el art. 5.1 y 4 TUE; que tiene sus raíces en el common

65 Así, Ludwigs (2020: 9/9). 
law y, sobre todo, en el derecho alemán (apdo. 124), y que —en una de sus versiones más conocidas - consta de tres subprincipios o escalones (idoneidad, necesidad y adecuación-ponderación), que son también reconocidos en otros ordenamientos jurídicos, como el francés, el español o el sueco (apdo. 125).

El BVerfG admite que la aplicación del principio de proporcionalidad por el TJ, con sus únicos dos escalones de la adecuación y la necesidad, no coindice completamente con la terminología y la dogmática alemanas. Es verdad que el tercer test de la proporcionalidad en sentido estricto apenas se utiliza como tal (apdo. 126), pero en casi todos los ámbitos del derecho de la Unión Europea la argumentación de la jurisprudencia del TJ dejaría un espacio para el análisis de las consecuencias fácticas de las decisiones de órganos públicos que aquel enjuicia: derechos fundamentales, discriminaciones indirectas derivadas de circunstancias fácticas, medidas de efecto equivalente en el campo de las libertades fundamentales, etc. (apdo. 152). Para el BVerfG, es precisamente la desaparición de la consideración de las consecuencias del PSPP sobre las políticas económicas de los Estados miembros lo que determina que el principio de proporcionalidad como canon de control pierda su sentido, pues su parte medular consiste en la ponderación de intereses contrapuestos (apdo. 138).

A mi juicio, el debate suscitado por la utilización que la sentencia comentada del BVerfG ha realizado del principio de proporcionalidad para delimitar las competencias de la Unión Europea y los Estados miembros se deja reconducir a cuatro cuestiones fundamentales: i) en primer lugar, vuelve a plantearse la vieja pregunta relativa a si hay espacio para el principio de proporcionalidad en el ámbito del derecho de organización y de las reglas relativas a la distribución de competencias entre organizaciones jurídico-públicas; ii) en segundo término, hay que preguntarse si en el ámbito del derecho de la Unión la proporcionalidad se aplica propiamente a la delimitación de competencias entre aquella y los Estados miembros, o es, más bien, un principio que se proyecta solo sobre la forma de ejercer sus competencias por los órganos de la Unión Europea (art. 5.1 y 4 TUE); iii) la tercera cuestión es la que se refiere a la concreta estructura del principio de proporcionalidad y a si, en concreto, pertenece a su esencia el tercer escalón de la ponderación o proporcionalidad en sentido estricto, $y$, iv) por último, hay que decidir qué es lo que hay que incluir en ese juicio comparativo de beneficios y perjuicios en que consiste la ponderación que habitualmente se explica como tercer escalón del principio de proporcionalidad. Analicemos sucintamente cada una de estas cuestiones en relación con la sentencia comentada.

i) La cuestión relativa a si al principio de proporcionalidad le corresponde algún papel en el ámbito del derecho de organización y de la 
distribución de competencias entre organizaciones jurídico-públicas no es nueva ${ }^{66}$. A veces se le ha dado respuesta con la afirmación tópica de que el campo propio de aplicación del principio de proporcionalidad es el de las relaciones entre el Estado y el ciudadano, entre el poder y la libertad garantizada por los derechos fundamentales, pero no el de las relaciones entre sujetos públicos titulares de ese poder. En Alemania es conocida la tesis, formulada expresamente en la sentencia Kalkar II del $\mathrm{BVerfG}^{67}$, que se refiere a que este principio no encuentra espacio regulativo en las relaciones federales entre el Bund y los Länder ${ }^{68}$. La afirmación se ha sometido, no obstante, a matices ${ }^{69}$.

En España, el Tribunal Constitucional ha declarado recientemente - en línea con lo que acaba de decirse- en una de las resoluciones que han enjuiciado la aplicación por el Estado del art. $155 \mathrm{CE}$ a la comunidad autónoma de Cataluńa por los acontecimientos que tuvieron lugar en el otońo de 2017, que el principio de proporcionalidad "conlleva, con carácter general, el planteamiento de tres juicios sucesivos (de idoneidad, de necesidad y de proporcionalidad en sentido estricto) que la doctrina constitucional ha aplicado sobre todo para controlar medidas limitativas de los derechos fundamentales»; pero el Tribunal rechaza la aplicación de dicho principio para examinar la constitucionalidad de las medidas adoptadas por el Estado y advierte de que va a utilizar un simple "canon de escrutinio externo»: «[...] la razonabilidad del juicio acerca de la relación de las medidas acordadas con la finalidad de defender el orden constitucional frente a su patente transgresión por un poder público $»^{70}$. Desde luego, no es posible, tampoco aquí, afirmar que esa declaración constituya una línea jurisprudencial consolidada y no desmentida por pronunciamientos igualmente recientes del mismo tribunal que han aplicado el principio de proporcionalidad como canon de examen de controles estatales en ámbitos competenciales de las comunidades autónomas ${ }^{71}$.

66 Véase, por ejemplo, Rodríguez de Santiago (2000: 111 y ss.).

67 Sentencia del BVerfG (Segundo Senado) de 22 de mayo de 1990 (caso Kalkar II), apdo. 105.

68 Sobre esto, sintéticamente, y en relación con el debate suscitado por la sentencia comentada, Ludwigs (2020: 2/9) y Callies (2020: 901).

69 Véase, por ejemplo, Heusch (2003: passim).

70 STC 89/2019, de 2 de julio, FJ 11.b.

71 Así, por ejemplo, SSTC 14/2018, de 20 de febrero (recurso de inconstitucionalidad frente a la Ley Orgánica 8/2013, de 9 de diciembre, para la mejora de la calidad educativa), FJ 10.c, alta inspección del Estado en materia educativa, y 55/2018, de 24 de mayo (recurso de inconstitucionalidad frente a la Ley 39/2015, de 1 de octubre, de procedimiento administrativo común de las administraciones públicas), FJ 11.e. 
Desde el punto de vista metodológico no puede excluirse, de hecho, que en las relaciones propias del derecho de organización y del reparto de competencias tengan cabida argumentaciones propias de la proporcionalidad o de la ponderación cuando en ellas se inserta algún "mandato de optimización», como puede ser el caso, por ejemplo, de la autonomía local ${ }^{72}$. Y desde la perspectiva del derecho positivo hay que aceptar, obviamente, que el principio de proporcionalidad debe aplicarse cuando el reparto normativo del poder lo invoca expresamente, como sucede en el art. 5.1 y 4 TUE.

ii) Un aspecto especialmente criticado de la sentencia que se comenta es el del objeto preciso del examen que había que realizar con ayuda del principio de proporcionalidad en el caso del PSPP: si se trataba de utilizarlo para delimitar la competencia monetaria de la Unión de la competencia de política económica de los Estados miembros; o si lo que había que analizar era si el ejercicio de la competencia monetaria realizado por el $\mathrm{BCE}$ cumplió con la exigencia de "no exceder de lo necesario" para alcanzar los objetivos de los tratados impuesta por el art. 5.4 TUE.

Sobre este punto - se dice- ha existido un malentendido evidente entre los tribunales ${ }^{73}$. Si se comparan la sentencia del TJ con la del BVerfG, está claro que la perspectiva del análisis del primero fue la del enjuiciamiento de la proporcionalidad en el ejercicio de la competencia monetaria del BCE (art. 5.4 TUE) (cómo se ejerce la competencia) ${ }^{74}$. Por el contrario, el BVerfG utiliza el principio de proporcionalidad para la delimitación de competencias (quién tiene la competencia), cuando examina si el BCE ha traspasado con el PSPP la frontera que separaría la política monetaria de la política económica ${ }^{75}$.

En mi opinión, esa diferenciación, en la práctica, puede resultar algo artificiosa. Si el art. 5.4 TUE tiene como finalidad proteger la competencia de los Estados miembros, una vulneración del principio de proporcionalidad en el ejercicio de la competencia de un órgano de la Unión Europea también tiene como resultado una ruptura de la delimitación de competencias entre la Unión y los Estados miembros ${ }^{76}$. Creo que esto es cierto. Pero, si se ańade a la relativa

supervisión estatal de decisiones autonómicas sobre servicios de Administración electrónica.

72 Así, por ejemplo, Velasco (2009: 59 y ss.).

73 Sobre esto, Pernice (2020: 3/8), Callies (2020: 901), Marzal (2020: 3/5).

74 Véase STJ (Gran Sala) de 11 de diciembre de 2018 (Weiss, asunto C-493/17), apdo. 71.

75 Véase sentencia del BVerfG (Segundo Senado) de 5 de mayo de 2020 (caso PSPP), apdo. 139.

76 Así, Ludwigs (2020: 5/9). 
indefinición del matiz (la distinción entre ejercicio y delimitación de competencias) la tantas veces criticada inseguridad metodológica de los resultados de la aplicación del principio de proporcionalidad, se tienen dos buenos ingredientes que explican el disenso.

iii) La sentencia del BVerfG que se comenta reprocha a la sentencia Weiss del TJ que, al hacer desaparecer del juicio de proporcionalidad las consecuencias del PSPP sobre las políticas económicas de los Estados miembros, este canon de control pierde su sentido, que es, precisamente, la ponderación de los intereses en conflicto. Con esto podría provocarse la impresión de que el BVerfG solo acepta como estructura del principio de proporcionalidad la versión alemana de este ${ }^{77}$, que incluye un tercer escalón que no existe siempre en la utilización que el TJ hace del control de proporcionalidad.

Ya se ha dicho que el BVerfG reconoce expresamente que la aplicación del principio de proporcionalidad por la jurisprudencia del $\mathrm{TJ}$ no coindice completamente con la terminología y la dogmática alemanas, y que en aquella el tercer test de la proporcionalidad en sentido estricto apenas se utiliza como tal. Pero también destaca el BVerfG - y esto es, a mi juicio, lo importanteque en casi todos los ámbitos del derecho de la Unión Europea la argumentación de la jurisprudencia del TJ deja un espacio para el análisis de las consecuencias fácticas de las decisiones públicas por él enjuiciadas. Es más, precisamente en la sentencia Weiss el TJ lleva a cabo un análisis que se presenta formalmente como un «tercer escalón» de la proporcionalidad, pero en el que no se hace referencia a los efectos del PSPP sobre la economía real de los Estados miembros (como exigía el BVerfG), sino a la seriedad del «riesgo de pérdidas» del programa de compras de bonos públicos ${ }^{78}$. Con ello el TJ ha ido más lejos de lo expresamente requerido por el art. 5.4 TUE, y es posible afirmar que la profundidad de la fundamentación de la STJ Weiss es mayor que la de otros muchos supuestos ${ }^{79}$.

Yo creo que no puede afirmarse correctamente que el BVerfG imponga a otros su concreta y ordenada versión del principio de proporcionalidad. Lo relevante para la sentencia del BVerfG sobre el PSPP no es que las consecuencias prácticas de ese programa de compra de bonos públicos sobre la economía de los Estados miembros se analicen formalmente en un tercer escalón del examen, sino que se incluyan en el enjuiciamiento. El canon de control puede estructurarse teóricamente de formas diversas, pero tiene que ser lo suficientemente incisivo o denso como para poder considerar esas consecuencias

Así, por ejemplo, Marzal (2020: 1/5).

78 STJ (Gran Sala) de 11 de diciembre de 2018 (Weiss, asunto C-493/17), apdos. 93-99.

79 Así, Nettesheim (2020: 1633). 
fácticas. Lo que reprocha la sentencia del BVerfG a la del TJ no es un defecto teórico en la construcción del principio de proporcionalidad, sino la (innegablemente) escasísima densidad del control ejercido por el TJ sobre las decisiones monetarias del $\mathrm{BCE}^{80}$. El BVerfG había pedido expresamente al TJ que incluyera esas consecuencias en su canon de escrutinio de las decisiones del $\mathrm{BCE}$ en la cuarta pregunta de su cuestión prejudicial ${ }^{81}$. Y, por cierto, sin hacer referencia a ningún tercer escalón de la proporcionalidad.

iv) Sorprende, no obstante, en la sentencia del BVerfG sobre el PSPP el empeño argumentativo que se emplea para demostrar que en el juicio de ponderación hay que incluir exclusivamente los efectos negativos que las medidas del BCE tienen para una política económica calificable gráficamente como «de austeridad» (favorecer la financiación de los Estados con más déficit público, la de empresas no competitivas que se mantendrán en el mercado por la facilidad de conseguir créditos ventajosos, etc. $)^{82}$. ¿ No deberían incluirse en el juicio de ponderación también los beneficios de carácter político, fiscal o económico derivados de esas decisiones monetarias? Ningún juicio de ponderación puede llevarse a cabo de forma adecuada si se decide a priori que se van a incluir en él solo los perjuicios y que se va a limitar el tipo de beneficios que pueden tenerse en cuenta ${ }^{83}$.

Este es, en realidad, un problema general del principio de proporcionalidad y de la ponderación como método de decisión en el derecho ${ }^{84}$. El órgano que ha de resolver por ponderación tiene que atender siempre a una relación de circunstancias potencialmente ilimitada, no delimitadas ni positiva (las que hay que tener en cuenta) ni negativamente (las que no deben tenerse en cuenta) por la norma. Se dice, de hecho, que, en el caso ideal, la ponderación ha de atender a "todas las circunstancias del caso concreto" para poder decidir cuál de los principios en conflicto recibe más peso o importancia a partir de ellas. El problema se soluciona en la práctica, como es obvio, atribuyendo a un órgano judicial el poder de decir «la última palabra» sobre la ponderación. Las circunstancias relevantes que había que tener en cuenta son, entonces, por

80 En sentido parecido, Jiménez-Blanco (2020: 170). Véase, también, la Sentencia del BVerfG (Segundo Senado) de 5 de mayo de 2020 (caso PSPP), apdos. 142-144.

81 Véase STJ (Gran Sala) de 11 de diciembre de 2018 (Weiss, asunto C-493/17), apdo. 16.

82 Sentencia del BVerfG (Segundo Senado) de 5 de mayo de 2020 (caso PSPP), apdos. 170-175.

83 Así, Poiares Maduro (2020: 4/7). En sentido parecido, Marzal (2020: 4/5) y Mayer (2020: 1124).

84 Sobre esto, por ejemplo, Rodríguez de Santiago (2000: 103-104). 
definición, las que ha tenido en cuenta ese órgano. Por eso se ha dicho que la ponderación desplaza el poder hacia el órgano que tiene la competencia de adoptar la última decisión. Y eso es, exactamente, lo que ha fallado en este caso, porque tanto el TJ como el BVerfG han querido decir la última palabra.

En definitiva, por las dudas expuestas sobre la utilización del principio de proporcionalidad para la delimitación de competencias (en lugar de para enjuiciar su ejercicio) y por la limitación del tipo de efectos que el BVerfG considera que deben incluirse necesariamente en el juicio de ponderación, es posible afirmar que a la sentencia que se comenta le falta una dogmática sobre la aplicabilidad de la proporcionalidad al PSPP tan sólida como para dar sobre él un golpe tan rotundo ${ }^{85}$. Quizá hubiera sido oportuno por parte del BVerfG formular una segunda cuestión prejudicial centrada en una más concreta pregunta sobre la proporcionalidad ${ }^{86}$. Que esa vía de cooperación entre tribunales podía haber tenido éxito lo demuestra la actuación de la Corte Constitucional italiana y el TJ en el conocido caso Taricco ${ }^{87}$.

\section{2. ¿ULTRA VIRES O SIMPLE ILEGALIDAD?}

En la parte de la sentencia del BVerfG en la que se expone con detalle el canon de control que va a utilizar el tribunal en su enjuiciamiento del PSPP (apdos. 98-115) se recapitulan los perfiles del examen del ultra vires, que proceden, fundamentalmente, de su jurisprudencia anterior: el presupuesto del ejercicio por el BVerfG del control del ultra vires es una vulneración manifiesta o suficientemente cualificada del principio de competencia de atribución (art. 5.1 TUE) por un órgano de la Unión Europea, lo que supone, por su parte, que la extralimitación competencial sea «evidente» y que conduzca a una alteración «estructuralmente relevante» del reparto de funciones en contra de las competencias de los Estados miembros. En principio, este será el caso cuando el ejercicio de la competencia por el órgano de la Unión Europea exija una reforma de los tratados conforme al art. 48 TUE o el uso de una cláusula evolutiva, supuestos ambos que exigen en Alemania una actuación del

85 Así, en relación solo con la falta de fundamento dogmático para la aplicación de la proporcionalidad a la delimitación de competencias, Ludwigs (2020: 4).

86 Así, con remisión al caso Taricco, Callies (2020: 901).

87 Véanse STJ (Gran Sala) de 8 de septiembre de 2015 (Taricco I, asunto C-105/14); STJ (Gran Sala) de 5 de diciembre de 2017 (Taricco II, asunto C-42/17), y Sentencia de la Corte Constitucional italiana 115/2018, de 10 de abril; aunque en este caso la primera cuestión prejudicial no la planteó la Corte Constitucional. 
legislador (apdo. 110). No se opone al carácter evidente de la extralimitación competencial la circunstancia de que su constatación sea el resultado de una interpretación cuidadosa y fundamentada con detalle (apdo. 113). Esto último, por lo pronto, ya me parece discutible: lo evidente, por definición, es tan claro que puede constatarse sin necesidad de razonamientos o explicaciones.

Y el Alto Tribunal alemán también destaca expresamente su obligación de benevolencia deferente con los posibles errores ajenos: el BVerfG debe igualmente respeto a las decisiones del $\mathrm{TJ}$ de las que pudiera discreparse con argumentos poderosos, pues el TJ deriva del art. 19.1 TUE un derecho a la tolerancia frente a sus errores; pero con el límite de lo que ya no se deje reconducir a principios metodológicos reconocidos y de lo que se presente, por tanto, como objetivamente arbitrario (apdo. 112). Esto es, por cierto, lo que explica el durísimo lenguaje que ha utilizado el BVerfG contra la decisión del TJ: «absolutamente incompresible», «objetivamente arbitraria», «metodológicamente inasumible»... El listón del respeto y la tolerancia se había puesto muy alto en la jurisprudencia anterior del $\mathrm{BVerfG}^{88}$; si ahora se quería saltar por encima de él, era necesario utilizar ese lenguaje ${ }^{89}$.

En este punto se encuentra, en mi opinión, la parte más débil y menos convincente de la argumentación del BVerfG. Aceptemos que las decisiones del BCE relativas al PSPP tendrían que haber tenido en cuenta y ponderado los efectos de esa medida monetaria sobre las políticas económicas de los Estados miembros y que no lo hicieron. ¿Es esto un ultra vires? Esto puede ser una ilegalidad formal (falta de motivación), pero que no se haya realizado el juicio de ponderación no significa que se haya invadido la competencia de los Estados miembros. La falta de motivación no puede identificarse automáticamente con la falta «evidente» de competencia, sino, como máximo, con la duda (hasta que se expongan adecuadamente las razones) sobre la posible incompetencia ${ }^{90}$.

Y algo semejante puede decirse del ultra vires que se imputa a la sentencia Weiss del TJ. Aceptemos que el TJ haya rebajado en exceso la densidad de su control sobre la actuación del BCE. Esto puede suponer una mala o pésima aplicación del derecho por parte del TJ, pero no una actuación fuera del ámbito de sus competencias. Precisamente, más motivos habría para hablar de un «defecto» en el uso de su jurisdicción que de una extralimitación en el

88 Sentencia del BVerfG (Segundo Senado) de 6 de julio de 2010 (caso Honeywell), apdo. 66.

89 Así, Haltern (2020: 821) y Nettesheim (2020: 1632).

90 Así, Sauer (2020: 7). También, Sarmiento (2020: 17-18). 
ejercicio de su poder jurisdiccional. Lo que está en cuestión aquí es, como máximo, una ilegalidad, pero no un ultra vires ${ }^{91}$. En el ámbito del derecho interno no se identifica la ilegalidad (ni siquiera la ilegalidad evidente) con la extralimitación competencial, ni en el derecho alemán ni en el derecho español; no está claro por qué la cosa tiene que ser distinta en el ámbito del derecho de la Unión ${ }^{92}$.

\section{LA CUESTIÓN DE LA DENSIDAD DEL CONTROL JUDICIAL SOBRE EL RESPETO POR EL BCE DE LOS LÍMITES DE SUS COMPETENCIAS}

Se deduce de lo que ya se ha expuesto que uno de los objetivos primordiales pretendidos por el BVerfG al plantear la cuestión prejudicial era el de conseguir del TJ una mayor intensidad de control y una menor deferencia en relación con el respeto por el BCE de los límites de su competencia monetaria. La utilización del principio de proporcionalidad era puramente instrumental para ese objetivo ${ }^{93}$.

El BVerfG aplica sobre este extremo una exigencia de su manera de entender el principio democrático: la "desconexión democrática» de los órganos independientes impone un intenso control judicial del mantenimiento de la actuación de esos órganos dentro de las fronteras de su poder. El BVerfG formula la idea en estos términos: la independencia de los bancos centrales supone una pérdida en el nivel de su legitimidad democrática que exige controlar estrictamente que sus decisiones se mantengan en el ámbito de sus competencias; el principio democrático impone un intenso control judicial relativo a que el BCE se mueve dentro de los límites de sus funciones ${ }^{94}$. La argumentación es perfectamente comprensible. Lo que no está claro es que el criterio pueda y deba trasladarse, sin más, del derecho constitucional alemán al ámbito de las reglas conforme a las cuales el TJ controla la actividad de los órganos independientes de la Unión Europea ${ }^{95}$.

Que el TJ reconozca amplísimos márgenes de apreciación a órganos de la Unión y sea extraordinariamente deferente al controlar sus actuaciones se

Así, Sauer (2020: 5-6) y Nettesheim (2020: 1633).

Así, Nettesheim (2020: 1632).

Así, Nettesheim (2020: 1633).

94 Sentencia del BVerfG (Segundo Senado) de 5 de mayo de 2020 (caso PSPP), apdo. 143.

${ }_{95}$ Así, Sauer (2020: 6). En sentido semejante, Nettesheim (2020: 1633). 
corresponde con la práctica habitual de aquel tribunal ${ }^{96}$. Y no de los últimos años, sino de las últimas seis décadas; un período de tiempo en el que, si algunos Estados miembros hubieran tenido algún reparo serio sobre el estándar de control o la metodología argumentativa utilizados por el TJ, podrían haber identificado esas cuestiones como objeto merecedor de reforma en los tratados (Sarmiento, 2020: 16). El problema de fondo es que todavía no se ha conseguido formular una dogmática manejable sobre la suficiencia de la densidad de control que impondría el art. 19 TUE (y también el art. 47 de la Carta de Derechos Fundamentales de la Unión Europea) al TJ ${ }^{97}$. Por otra parte, es innegable que también el BVerfG se muestra deferente al ejercer su control cuando se someten a su enjuiciamiento cuestiones y decisiones complejas, por ejemplo, en materia de política fiscal y económica ${ }^{98}$.

Desde un punto de vista pragmático, no obstante, a posteriori es discutible si el TJ podía haber mostrado una mayor disposición a atender a los argumentos formulados seriamente en la cuestión prejudicial formulada por el BVerfG y a adaptar en algo su canon de control a lo que este le pedía. El debilísimo estándar de control finalmente utilizado implicaría un riesgo que el TJ podría haber calculado mejor ${ }^{99}$.

\section{DINERO}

\section{LA PROHIBICIÓN DE LAS AYUDAS FINANCIERAS A LOS ESTADOS MIEMBROS (ART. 123 TFUE)}

Varias de las preguntas formuladas en la cuestión prejudicial del BVerfG ponían también en conexión con el ultra vires imputado a las decisiones del BCE la eventual vulneración por el PSPP de la prohibición de ayudas financieras por parte del BCE o de los bancos centrales nacionales a los Estados miembros (art. 123.1 TFUE). Haciendo uso de los criterios ya establecidos en la STJ (Gran Sala) de 16 de junio de 2015 (Gawweiler, asunto C-62/14), la STJ Weiss argumenta, en síntesis, i) que la compra de bonos en el mercado secundario no es equivalente a la compra de deuda pública en el primario,

\footnotetext{
Sobre esto, por ejemplo, Soriano (2020: 11, passim).

Así, en relación solo con el art. 19 TUE, Nettesheim (2020: 1633).

Así, Callies (2020: 903).

99 En este sentido, Haltern (2020: 822), Callies (2020: 903), Möllers (2020: 3/4) y Poiares Maduro (2020: 6/7).
} 
porque el PSPP incluye garantías para limitar la previsibilidad de las adquisiciones por los operadores privados, garantías que aseguran que estos no se comportan como meros intermediarios ${ }^{100}$, y ii) que, aunque el PSPP puede contribuir parcialmente a facilitar la financiación de un Estado miembro en condiciones más favorables que las de mercado, se incluyen en el programa también otras garantías dirigidas a no neutralizar el incentivo a la aplicación de una sana política presupuestaria ${ }^{101}$.

La sentencia del BVerfG, de mala gana, invocando la obligación —a la que se ha hecho referencia más arriba — de ser tolerante ante errores del TJ, aunque estos pudieran suscitar reparos importantes, acepta la argumentación de la STJ Weiss y desestima en este punto las demandas de amparo ${ }^{102}$. Para el BVerfG las decisiones del BCE sobre el PSPP no vulneran «de forma cualificada» el art. 123.1 TFUE. Alguno de los criterios a los que se hace referencia en la STJ Weiss serían inocuos, pero, en una visión general, otros de los que se utilizan para formular este juicio podrían servir para evitar que se sortee la prohibición contenida en ese precepto. En esa medida, tampoco el TJ se situaría con su decisión fuera de la competencia que le confiere el art. 19.1 TUE ${ }^{103}$.

\section{LA EVENTUAL DISTRIBUCIÓN DE PÉRDIDAS}

En las demandas de amparo solo la cuestión relativa a la distribución ilimitada de riesgos entre los bancos centrales nacionales del Eurosistema se había hecho valer no a través de la reserva del control del ultra vires, sino de la preservación de la identidad constitucional alemana. Recuérdese lo que se ha expuesto arriba sobre las tres reservas formuladas por el BVerfG a la primacía del derecho de la Unión: nivel de protección de los derechos fundamentales, ultra vires y respeto a la identidad constitucional. Todos los demás reproches dirigidos por los recurrentes al PSPP se encauzan por la vía del ultra vires. Este del eventual reparto de pérdidas se reconduce a la preservación de la identidad constitucional alemana.

La argumentación consistía en la pretensión de acreditar que posibles pérdidas que surgieran en el marco del PSPP pudieran ser «socializadas» $a$

100 Véase STJ (Gran Sala) de 11 de diciembre de 2018 (Weiss, asunto C-493/17), apdos. 109-128.

101 Véase STJ (Gran Sala) de 11 de diciembre de 2018 (Weiss, asunto C-493/17), apdos. 129-144.

102 Sobre esto, Nettesheim (2020: 1634).

103 Sentencia del BVerfG (Segundo Senado) de 5 de mayo de 2020 (caso PSPP), apdo. 197. 
posteriori mediante una decisión del BCE. Con ello se afectaría al principio democrático ( $y$, con ello, a la identidad constitucional), en la medida en que la recapitalización de un banco nacional comprometiera recursos presupuestarios alemanes de forma que se viera afectado el poder presupuestario del Parlamento federal, que debe seguir siendo responsable de (y decidir sobre) los recursos y los gastos esenciales del Estado ${ }^{104}$. Por expresarlo de forma imprecisa, pero gráfica: de las decisiones de un Estado miembro no puede terminar siendo responsable económico el pueblo de otro Estado miembro.

La STJ Weiss inadmite la cuestión por "meramente hipotética» ${ }^{105}$. Y la sentencia del BVerfG comentada, después de analizarla, la desestima: el reparto del riesgo entre los bancos centrales nacionales no permite una redistribución de las deudas nacionales entre los Estados miembros de la eurozona y, por eso, no afecta a la responsabilidad presupuestaria global del Parlamento federal ${ }^{106}$. Si se lee con detenimiento la STJ Weiss, no obstante, es fácil caer en la cuenta de que el TJ no cuestiona la facultad del BCE de adoptar una decisión sobre el reparto a posteriori de cargas, sino que se limita a constatar que en el derecho primario no hay previsto ningún reparto de pérdidas y que el $\mathrm{BCE}$, hasta ahora, tampoco ha adoptado ninguna decisión relativa a su distribución ${ }^{107}$. La constatación del BVerfG según la cual una decisión de ese tipo por parte del BCE supondría una modificación de los tratados (art. 48 TUE) es más un deseo que una reproducción de la opinión del TJ; y, de paso, una clara advertencia sobre cómo entiende el BVerfG la identidad constitucional alemana ${ }^{108}$.

\section{CONCLUSIÓN. Y AHORA, ¿¿QUÉ? LA RESPUESTA EUROPEA FRENTE A LA CRISIS DEL CORONAVIRUS}

Como se ha expuesto más arriba, el Gobierno y el Parlamento federales ya han considerado que las explicaciones ofrecidas por el BCE en relación con la proporcionalidad de sus decisiones sobre el PSPP satisfacen las exigencias de motivación impuestas por la sentencia que se comenta del BVerfG. Merece la pena dirigir la atención sobre la circunstancia de que el BVerfG no haya

104 Sentencia del BVerfG (Segundo Senado) de 5 de mayo de 2020 (caso PSPP), apdo. 104.

105 STJ (Gran Sala) de 11 de diciembre de 2018 (Weiss, asunto C-493/17), apdo. 166.

106 Sentencia del BVerfG (Segundo Senado) de 5 de mayo de 2020 (caso PSPP), apdo. 222.

107 STJ (Gran Sala) de 11 de diciembre de 2018 (Weiss, asunto C-493/17), apdos. $162-163$.

108 Así, Nettesheim (2020: 1634). 
querido entrar a analizar él mismo la eventual desproporción de las decisiones del BCE, para llegar a la posible conclusión irremediable de que las medidas del BCE vulneraban el principio de proporcionalidad ${ }^{109}$. No cabe excluir que, con la información de que disponía y de la que se da buena cuenta en la fundamentación de la sentencia, el BVerfG hubiera sido capaz de realizar ese juicio por sí mismo. Esto le hubiera ahorrado la crítica relativa a que declarar un ultra vires como consecuencia de un defecto formal de motivación subsanable supone forzar hasta lo inaceptable el concepto de extralimitación «evidente y estructuralmente relevante».

Pero, al permitir la posibilidad de que el BCE examinara y motivara $a$ posteriori desde la perspectiva de la proporcionalidad sus medidas monetarias relativas al PSPP, el BVerfG dejaba abierta una última oportunidad para arreglar las consecuencias del aparatoso desencuentro entre los tribunales. Si la situación quedara en el punto en el que ahora se encuentra, a efectos prácticos — como ya se ha dicho-, aquí habría terminado el ruidoso incidente. Quedaría, cierto es, el efecto secundario de alentar contra el TJ a los Estados miembros que se alejan de las reglas del Estado de derecho (Dieter Grimm, 2020: 949).

Por otra parte, antes de que se hiciera pública la sentencia del BVerfG sobre el PSPP el BCE ya había adoptado, en marzo de 2020, como primera reacción europea frente a la crisis que a la eurozona planteaba la pandemia del coronavirus, una medida que se situaba en la misma línea que las anteriores, ahora bajo las siglas PEPP (Pandemic Emergency Purchase Programme). Inmediatamente se llamó la atención sobre la circunstancia de que el nuevo PEPP no cumplía alguno de los requisitos destacados por la STJ Weiss, y, en paralelo, aunque con cierta independencia, por la sentencia del BVerfG sobre el PSPP ${ }^{110}$ para que esos programas de compra de activos se consideren compatibles con el art. 123 TFUE ${ }^{111}$ : el PEPP no establece, por ejemplo, el límite máximo de compra del $33 \%$ de una determinada emisión de bonos, y, además, permite compras que no se realizan con arreglo a la clave para la suscripción del capital del BCE. El conflicto ya está preparado para volver a repetirse...

El BVerfG se ha equivocado - a mi juicio- en la forma de transmitir su mensaje, pero la severidad del golpe asestado ha servido, al menos, para que su contenido quede claro: el BVerfG (y, con él, necesariamente, el Estado alemán) no está dispuesto a aceptar que se sigan sustituyendo los procesos

109 Lo destaca Sarmiento (2020: 17-18).

110 Sentencia del BVerfG (Segundo Senado) de 5 de mayo de 2020 (caso PSPP), apdo. 216.

111 Así, Poiares Maduro (2020: 4/7), Nettesheim (2020: 1634) y Callies (2020: 898). 
políticos y democráticos en la Unión Europea por el activismo de sus órganos independientes. Para el BVerfG esto es una cuestión innegociable relativa a la democracia en Alemania y en Europa.

Es muy probable que la claridad del mensaje ejerciera una presión relevante (no es posible saber si calculada o no por el BVerfG al dictar su sentencia) para que el Consejo Europeo recorriera decididamente las mencionadas vías de la política con el objeto de alcanzar las ambiciosas conclusiones en las que terminó su reunión extraordinaria de los días 17 a 21 de julio de $2020^{112}$. No es, obviamente, este lugar adecuado para el análisis detallado del pacto. Solo interesa destacar alguno de sus contenidos. Entre otros acuerdos que se sitúan bajo el título doble de "Next Generation EU» y Marco Financiero Plurianual, por primera vez, se autorizará a la Comisión a contraer empréstitos en los mercados de capitales en nombre de la Unión por valor de 750000 millones de euros ${ }^{113}$. Esta era la segunda y más seria respuesta europea a la crisis económica derivada de la pandemia.

De eso es, precisamente, de lo que se habla, por debajo de los tecnicismos del principio de proporcionalidad y del ultra vires, en la sentencia del BVerfG sobre el PSPP: de acuerdos políticos sólidos para dar estabilidad a las respuestas a las crisis, de recursos propios de la Unión para que sea posible compartir los riesgos $^{114}$, del traslado a las democracias nacionales de las decisiones necesarias para aumentar esos recursos ${ }^{115}$ (conforme a lo previsto en el art. 311 TFUE), etc.

La «metodología» en la sentencia comentada del BVerfG es solo un instrumento para hablar de "democracia». Y la democracia nació, en parte, con la competencia presupuestaria de los Parlamentos, esto es, en relación con el «dinero».

\section{BIBLIOGRAFÍA}

Callies, Ch. (2020). Konfrontation statt Kooperation zwischen BVerfG und EuGH? Zu den Folgen des Karlsruher PSPP-Urteils. Neue Zeitschrift für Verwaltungsrecht, 897-904.

112 Sobre este acuerdo, sintéticamente, Urrea Corres (2020: 170-173).

113 Véase el citado documento de las conclusiones (EUCO 10/20, CO EUR 8, CONCL 4), A5.

114 Sobre esto, sintéticamente, Poiares Maduro (2020: 5-6/7). Sobre el aumento de los recursos propios de la Unión, véase el citado documento de las conclusiones (EUCO 10/20, CO EUR 8, CONCL 4), A29 y apdo. 145 y ss.

115 Véase el citado documento de las conclusiones (EUCO 10/20, CO EUR 8, CONCL 4), A33. 
Feichtner, I. (2020). The German Constitutional Court's PSPP Judgment: Impediment and impetus for the democratization of Europe. German Law Journal, 21, 1090-1103. Disponible en: https://doi.org/10.1017/glj.2020.60.

Fromage, D. (2020). Weiss: the Bundesverfassungsgericht's over-expansive interpretation of the Bundestag's 'responsibility for integration' and the need to adapt judicial review procedures to the E(S)CB's specificities. EULawLive, 18, 2-15.

Grimm, D. (2020). A Long Time Coming. German Law Journal, 21, 944-949. Disponible en: https://doi.org/10.1017/glj.2020.55.

Haltern, U. (2020). Ultra-vires-Kontrolle im Dienst europäischer Demokratie. Neue Zeitschrift für Verwaltungsrecht (NVwZ), 39 (12), 817-823.

Heusch, A. (2003). Der Grundsatz der Verhältnismäßigkeit im Staatsorganisationsrecht. Berlin: Duncker and Humblot.

Jellinek, G. (2000). Teoría General del Estado (traducción de Fernando de los Ríos de la 2. ${ }^{\text {a }}$ ed. alemana de 1911). México: Fondo de Cultura Económica.

Jiménez-Blanco, A. (2020). La compra de deuda pública por el Banco Central Europeo: notas sobre la Sentencia del Tribunal Constitucional Federal de Alemania de 5 de mayo de 2020. Revista de Administración Pública, 212, 147-180. Disponible en: https:// doi.org/10.18042/cepc/rap.212.05.

Ludwigs, M. (2020). The consequences of the judgement of 5 May 2020 of the Second Senate of the German Constitutional Court. Versión escrita del Public Hearing at the Committee on Legal Affairs, Committee on Constitutional Affairs, 14 de julio de 2020.

Marzal, T. (2020). Is the BVerfG PSPP decision 'simply not comprehensible'? Verfassungsblog.de [blog], 9-5-2020. Disponible en: https://bit.ly/3x0mcxU.

Mayer, F. C. (2020). To boldly go where no court has gone before. The German Federal Constitutional Court's ultra vires decision of May 5, 2020. German Law Journal, 21, 1116-1127. Disponible en: https://doi.org/10.1017/glj.2020.58.

Möllers, Ch. (2020). Sollte die EU-Kommission Deutschland wegen des Karlsruher Ultra-Vires-Urteils verklagen? Contra. Verfassungsblog.de [blog], 16-5-2020. Disponible en: https://bit.ly/3uVWEQX.

Nettesheim, M. (2020). Das PSPP-Urteil des BVerfG - ein Angriff auf die EU? Neue Juristische Wochenschrift, 1631-1634.

Pernice, I. (2020). Sollte die EU-Kommission Deutschland wegen des Karlsruher Ultra-Vires-Urteils verklagen? Pro. Verfassungsblog.de [blog], 16-5-2020. Disponible en: https:// bit.ly/2T2TyxA.

Poiares Maduro, M. (2020). Some Preliminary Remarks on the PSPP Decision of the German Constitutional Court. Verfassungsblog.de [blog], 6-5-2020. Disponible en: https://bit.ly/3giBiYM.

Roca, M. ${ }^{a}$ J. (2020). La sentencia del Tribunal Constitucional Federal Alemán sobre el Programa de Compra de Bonos por el Banco Central Europeo: el control ultra vires y la primacía del Derecho europeo. Saggi - Diritto Pubblico Comparato ed Europeo online, 2845-2856.

Rodríguez de Santiago, J. M. a (2000). La ponderación de bienes e intereses en el Derecho administrativo. Madrid: Marcial Pons. 
Ruffert, M. (2015). Europarecht: Vorabentscheidung des EuGH zum OMT-Program. Juristische Schulung, 758-760.

- (2017). Europarecht: Vorlagebeschluss zu den Anleihekäufen der EZB. Juristische Schulung, 1229-1232.

- (2020). Editorial: Für eine starke Rechtsgemeinschaft. Neue Justistische Wochenschrift, $21,3$.

Sarmiento, D. (2020). Requiem for judicial dialog: the German Federal Constitucional Court's judgment in the Weiss case and its European implications. EU Law Live, 16, 9-20.

Sauer, H. (2020). Substantive EU law review beyond the veil of democracy: the German Federal Constitutional Court ultimately acts as Supreme Court of the EU. EU Law Live, 16, 2-8.

Soriano, J. E. (2020). Deutschland über alles: una canción entonada por el Tribunal Constitucional alemán que invade Europa. La Ley. Unión Europea, 82, 1-12.

Streinz, R. (2019). Europarecht (11. a ed.). Heidelberg: CF Müller GmbH.

Urrea Corres, M. (2020). La Unión Europea antes y después de la pandemia: de la fatiga de integración al impulso político del proyecto a través del plan de rescate. En VV. AA. 20 reflexiones juridicas en tiempo de confinamiento. Liber amicorum en homenaje a Cristina Izquierdo Sans (pp. 163-176). Madrid: Los Autores.

Velasco, F. (2009). Derecho local. Sistema de fuentes. Madrid: Marcial Pons.

Wahl, R. (2013). Los últimos cincuenta años de Derecho administrativo alemán. Madrid: Marcial Pons. 